This item was submitted to Loughborough's Research Repository by the author.

Items in Figshare are protected by copyright, with all rights reserved, unless otherwise indicated.

\title{
Highly linear microstrip wideband bandpass filter with switchable notched band for wireless applications
}

PLEASE CITE THE PUBLISHED VERSION

http://dx.doi.org/10.1002/mop.27585

PUBLISHER

(C) Wiley Periodicals

VERSION

AM (Accepted Manuscript)

\section{PUBLISHER STATEMENT}

This work is made available according to the conditions of the Creative Commons Attribution-NonCommercialNoDerivatives 4.0 International (CC BY-NC-ND 4.0) licence. Full details of this licence are available at: https://creativecommons.org/licenses/by-nc-nd/4.0/

\section{LICENCE}

CC BY-NC-ND 4.0

\section{REPOSITORY RECORD}

Rabbi, K., L. Athukorala, C.J. Panagamuwa, J.C. Vardaxoglou, and D. Budimir. 2019. "Highly Linear Microstrip Wideband Bandpass Filter with Switchable Notched Band for Wireless Applications". figshare. https://hdl.handle.net/2134/22681. 


\title{
Highly Linear Microstrip Wideband Bandpass Filter with Switchable Notched band for Wireless Applications
}

\author{
K. Rabbi ${ }^{*}$ L. Athukorala ${ }^{*}$ C. Panagamuwa ${ }^{\#}$ J. C. Vardaxoglou* and D. Budimir ${ }^{*}$, \\ "Wireless Communications Research Group, School of Electronics and Computer Science, \\ University of Westminster, 115 New Cavendish Street, London, W1W 6UW, UK. \\ ${ }^{\#}$ Wireless Communication Research Group, Loughborough University, Loughborough, UK
}

\begin{abstract}
This paper presents a highly linear reconfigurable bandpass filter embedded with a switchable notch structure to get a band-notched characteristic at a specified frequency. A single PIN diode (BAP65-02) is used for the purpose of switching the notch. An optical switch, comprised of a silicon dice activated using near infrared light is also investigated as an alternative to the pin diode. While the PIN diode or the optical switch is in the ON state this reconfigurable filter behaves as a bandpass filter with a notch at $2.4 \mathrm{GHz}$ in order to reject WLAN interference while a full band response is obtained in the OFF state. The proposed filter is able to achieve good linearity using pin diode with IIP3 of $47 \mathrm{dBm}$ and no significant loss. A prototype is fabricated, and measured results are compared to simulations. A good agreement has been achieved between simulated and measured results.
\end{abstract}

Index Term-Reconfigurable filters, switchable notch, WLAN, microstrip filters, optical switch, pin diode.

\section{INTRODUCTION}

Radio frequency is a valuable and finite resource and, today, there is simply not enough to satisfy demand. The escalating deployment of wireless networking technology as well as other wireless technologies in the same spectrum is rapidly increasing radio frequency interference, threatening the data throughput performance. This is particularly true at GSM, GPS, UMTS, LTE, and WLAN. For instance, the wireless service standard IEEE 802.16a which addresses frequencies from $2 \mathrm{GHz}$ to $11 \mathrm{GHz}$, where the dominant bands are licensed bands at $2.3 \mathrm{GHz}$ (WCS), 2.5 to $2.7 \mathrm{GHz}$ (MMDS) and unlicensed bands at $2.4 \mathrm{GHz}$ (ISM), where WLAN and LTE bands operate as well [1]. An ideal solution in such circumstances is a compact bandpass filter with a rejection notch that can be switched to a specified band. Currently, electronically reconfigurable or tunable microwave filters are attracting growing 
attention for development because of their improving capability with reduced cost and size. The pin diode offers high power handling capability, quick switching speed as well as providing $\mathrm{Q}>50$ below $10 \mathrm{GHz}$ with reduced cost, easier packaging and a lower bias voltage [2]. In contrast, optically controlled silicon switches offer high power handling capability, immunity to electromagnetic interference, excellent isolation between the microwave and switch control circuits and very low distortion [3]. Recent research into reconfigurable or tunable microstrip resonator/filter based on PIN/optical switch/varactor diodes include work presented in [2]-[7] where various forms of reconfigurability or tunability have been quoted for various structures. To date, several works have been presented on the development of reconfigurable filters structure but the filter linearity has not been investigated.

In this paper, a highly linear bandpass filter with a switchable notched band using a single pin diode and an optical switch with low loss, significantly low distortion and high switching speed. Two identical filters were fabricated, where one was testing using a pin diode and the other employed a highly linear optical switch. Simulation and experimental results have been presented to validate the argument. An optically activated silicon switch is used as an alternative for comparison purposes.

\section{PROPOSED FILTER STRUCTURES}

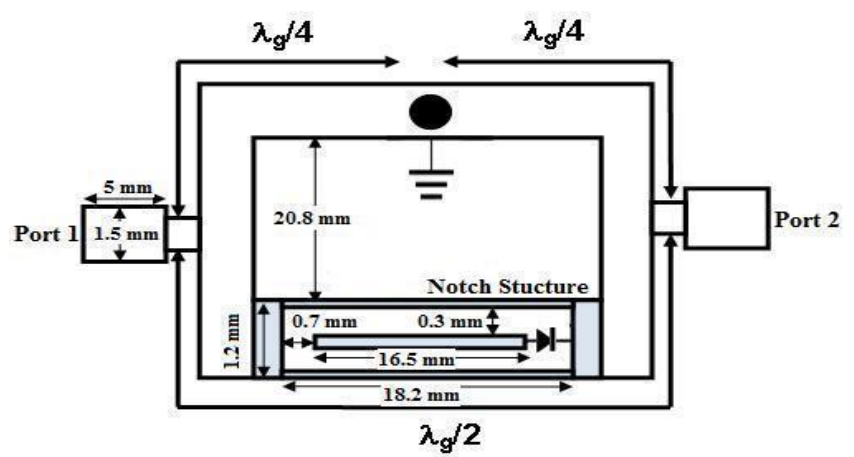

Figure 1 Layout of the proposed Bandpass filter with switchable notch structure

As depicted in Fig. 1, the configuration of the proposed bandpass filter composed of a folded single $\lambda_{g} / 2$ resonator, which is positioned between a pair of folded $\lambda_{g} / 4$ short circuited resonators. The filter is inductively coupled to the source and load as illustrated and is excited via ports 1 and 2 , where $Z_{0}=50 \Omega$. Compactness of this filter is attained through the reduction of filter length and width. In addition, two folded $\lambda_{g} / 4$ resonators are shorted to a common ground point in order to simplify and miniaturize the filter. The filter is designed to have a 3 $\mathrm{dB}$ passband from $698-2700 \mathrm{MHz}$ with a mid-band frequency of $1.7 \mathrm{GHz}$. The electrical length of the two $\lambda_{g} / 4$ length and the $\lambda_{g} / 2$ resonators have been calculated at a centre 
frequency of $1.7 \mathrm{GHz}$ and the filter line impedance was $57 \Omega$, which corresponded to lines of width $1.2 \mathrm{~mm}$. An equivalent circuit of the proposed bandpass filter is presented in Fig 2.

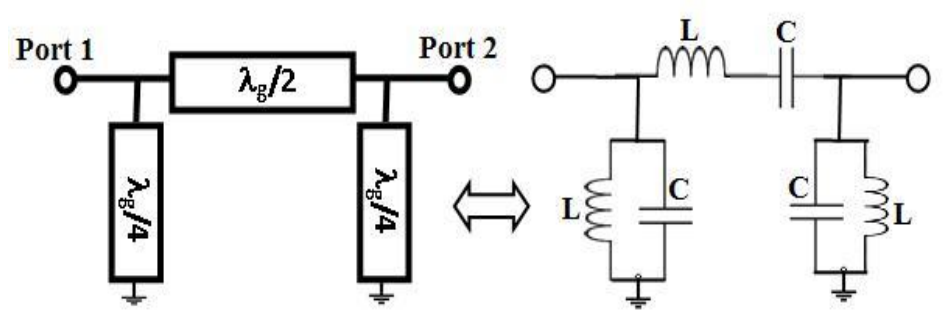

Figure 2 Equivalent circuit of the proposed bandpass filter.

The equivalent circuit in Fig. 2 is composed of one element section $\lambda_{g} / 2$ wavelength with characteristic impedance $\mathrm{Z}_{\mathrm{A}}$ and two $\lambda_{g} / 4$ short-circuited stubs with characteristic impedance $\mathrm{Z}_{\mathrm{B}}$. The terms $\mathrm{M}_{\mathrm{A}}$ and $\mathrm{M}_{\mathrm{B}}$ represent transmission matrix of $\mathrm{Z}_{\mathrm{A}}$ and $\mathrm{Z}_{\mathrm{B}}$, respectively:

$$
\begin{aligned}
M_{A} & =\left[\begin{array}{cc}
\cos \theta_{0} & j Z_{A} \sin \theta_{0} \\
j \frac{\sin \theta_{0}}{Z_{A}} & \cos \theta_{0}
\end{array}\right] \\
M_{B} & =\left[\begin{array}{cc}
1 & 0 \\
\frac{1}{j Z_{B} \tan \theta_{0}} & 1
\end{array}\right]
\end{aligned}
$$

where $\theta_{0}$ is the electrical length at the centre frequency. Therefore, the ABCD matrix can be expressed by multiplication of the sub-sections in sequence as shown,

$$
\mathrm{M}_{0}=\left[\begin{array}{ll}
A_{0} & B_{\mathrm{o}} \\
C_{0} & D_{0}
\end{array}\right]=\mathrm{M}_{\mathrm{B}} \times \mathrm{M}_{\mathrm{A}} \times \mathrm{M}_{\mathrm{B}}
$$

Finally, the scattering matrix can be derived by,

$$
\begin{aligned}
& S_{11}=\frac{A_{0}+B_{0} / Z_{0}+C_{0} Z_{0}-D_{0}}{A_{0}+B_{0} / Z_{0}+C_{0} Z_{0}+D_{0}} \\
& S_{21}=\frac{2\left(A_{0} D_{0}-B_{0} C_{0}\right)}{A_{0}+B_{0} / Z_{0}+C_{0} Z_{0}+D_{0}}
\end{aligned}
$$

\section{PROPOSED NOTCH STRUCTURE AND SWITCHING ELEMENTS}

To reject the undesired WLAN signal at $2.4 \mathrm{GHz}$, a section of transmission line with an embedded open stub is added as illustrated in Fig 1. The PIN diode is placed at the open-end of the stub as shown in Fig 1. When the PIN diode is in the forward bias or ON state, length of the stub is effectively elongated and therefore, the stub presents a short circuit at the main 
transmission line and acts as an open-circuited stub which contributes a transmission zero when its electrical length is about $90^{\circ}$ at the desired frequency. In contrast, in reverse bias or OFF state, there is no connection between the open stub and the main transmission line and the section gives an all pass response. On the other hand, an optical switch is overlaid in the place of pin diode with $1 \mathrm{~mm}$ x $3 \mathrm{~mm}$ silicon wafer. When the optical switch is in the ON state, the open stub generates a transmission zero at $2.4 \mathrm{GHz}$ within the specified passband and conversely acts same as pin diode in the OFF state.

In this paper, we investigate and compare the filter performance with pin diode switches and optical switches. Pin diodes are popular switching elements, especially in MIC designs, where in addition to high switching speed, they offer ruggedness. Equivalent circuits of the pin diode in the ON and OFF states are given in Fig. 3. In the ON state, the pin diode is essentially a current controlled resistor, whose resistance may be described by (5), where $k$ is a device constant, $I_{F}$ is the forward bias current and $\tau$ is the minority carrier lifetime [9]. In the OFF state, there is a large series resistance in parallel with a capacitance $C_{P}$, which degrades the high frequency isolation of the device.

$$
R_{S}=\frac{k}{\tau l_{F}}
$$

The nonlinearity introduced by a pin switch in the ON state is a function of the forward bias current $I_{F}$ and the RF current $i_{f}$. Generally, better linearity may be obtained when the extent of bias current modulation by the RF current decreases. The modulation effect can be minimised by deliberately operating at a high forward bias current [9]. On the other hand, the optical switch consists of a 1 x $3 \mathrm{~mm}$ n-type doped silicon wafer whose conductivity may be altered with illumination. It may be modelled with an equivalent circuit given in Fig. 4. Experimental data suggests that $R_{G}$ and $R_{S}$ decrease when the optical switch is ON while $C_{G}$ and $C_{S}$ increase [2]. In [10], the performance of a single optical switch was evaluated and was found to have an overall insertion-loss of around $0.68 \mathrm{~dB}$ in the $\mathrm{ON}$ state (under $200 \mathrm{~mW}$ of optical power). In the OFF state, the total series resistance increased significantly while $C_{G}$ and $C_{S}$ decreased. The EM simulations however were conducted with an open gap to model the switch in the OFF state and a bridged gap to model the switch in the ON state.

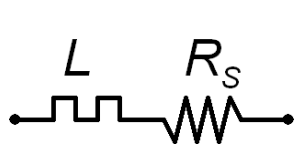

(a)

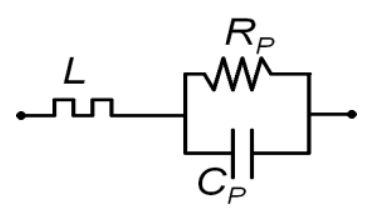

(b)

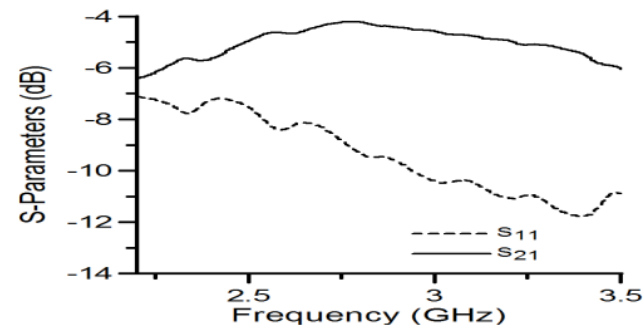

(c)

Figure 3 Equivalent circuit of pin diode in the (a) ON [forward bias] state, (b) OFF [reverse bias] state, (c) Magnitude response of the pin switch in the ON state. 


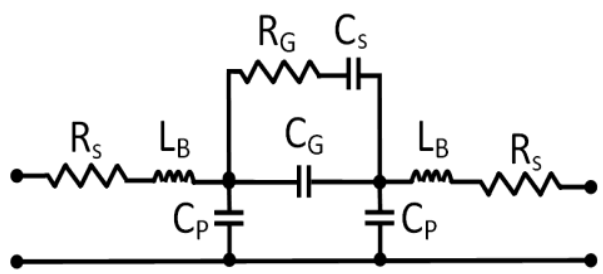

(a)

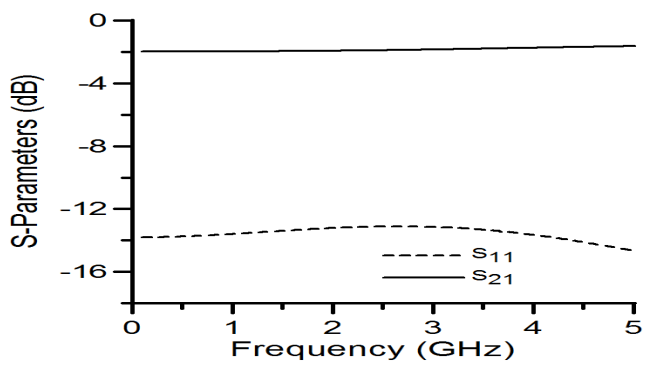

(b)

Figure 4 (a) Equivalent circuit of optical switch and (b) Magnitude response of the optical switch in the ON state.

\section{SIMULATION AND EXPERIMENTAL RESULTS}

To validate the circuit concept, a prototype filter is designed and fabricated on Rogers substrate (RO3010) with a thickness of $0.635 \mathrm{~mm}$, relative dielectric constant of $10.2, \tan \delta=$ 0.0023 , the metallization thickness of $0.017 \mathrm{~mm}$ and simulated using em sonnet ${ }^{\mathrm{TM}}$ and tested with a single pin diode (BAP65-02) and an optical switch for switching the notch in the passband. The overall filter dimension in millimetres is $21.8 \mathrm{~mm} \times 22 \mathrm{~mm}$. In our experiment, the pin diode was modelled by using a capacitor of value $0.8 \mathrm{pF}$ in the OFF state and a resistor value of $0.9 \Omega$ in the ON state [11]. Conversely, the silicon wafer has a conductivity of $35.2 \mathrm{mS} / \mathrm{m}$ in the dark state and a conductivity of $150.4 \mathrm{~S} / \mathrm{m}$ when optically activated [2]. The full wave simulated S-parameters of the filter in ON/OFF states together with the corresponding measurements, taken with Agilent vector network analyzer E38361A for pin diode and Anritsu Lightning 37397D Vector Network Analyzer for optical switch are shown in Fig. 5. A photograph of the fabricated filter is shown in Fig. 6. The measured passband insertion-loss of the bandpass filter was $0.8 \mathrm{~dB}$. The notch rejection at $2.41 \mathrm{GHz}$ in the $\mathrm{ON}$ state was observed at approximately $20 \mathrm{~dB}$. In contrast, using optical switch, the notch rejections were observed at 2.42 at approximately $18 \mathrm{~dB}$ and passband insertion-loss of the bandpass filter was $0.5 \mathrm{~dB}$. The small discrepancies between the simulated and measured responses may be attributed to the various fabrication errors involved.

For linearity validation of pin switch, the third order intermodulation performance was assessed by the two-tone test setup illustrated in Fig. 7. The test was conducted with the two tones at $1.99 \mathrm{GHz}$ and $2.01 \mathrm{GHz}$, with a forward bias voltage of $30 \mathrm{~V}$ with a DC isolation resistance of $1 \mathrm{k} \Omega$ to prevent RF leakage into the DC supply. The input and output referred third-order intercept points were measured at $47 \mathrm{dBm}$ and $42 \mathrm{dBm}$, respectively, as shown in Fig. 7. High linearity of the optical switch has already been verified in [10] where a thirdorder intercepts as high as $63 \mathrm{dBm}$. Furthermore, the IIP3 of the optically switched filter is expected to be even better due to the higher overall linearity of the optical switch. 


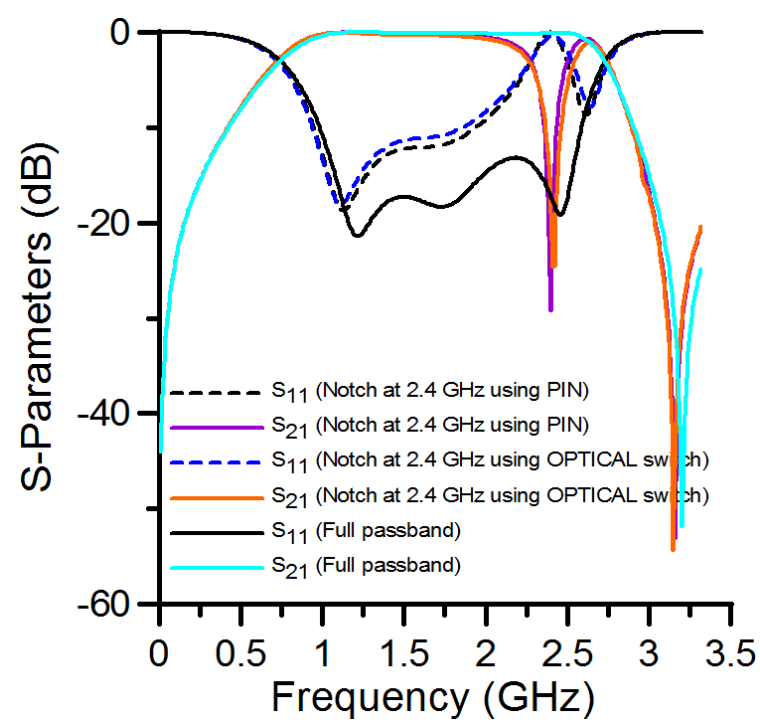

(a)

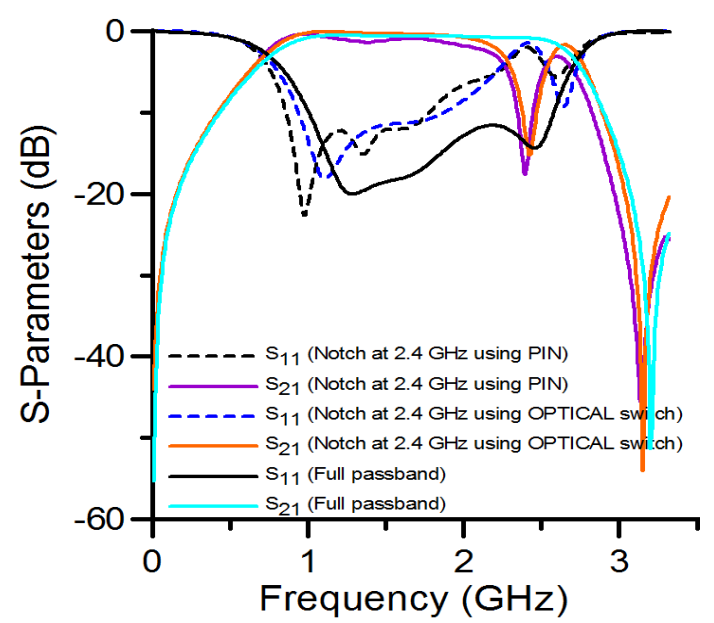

(b)

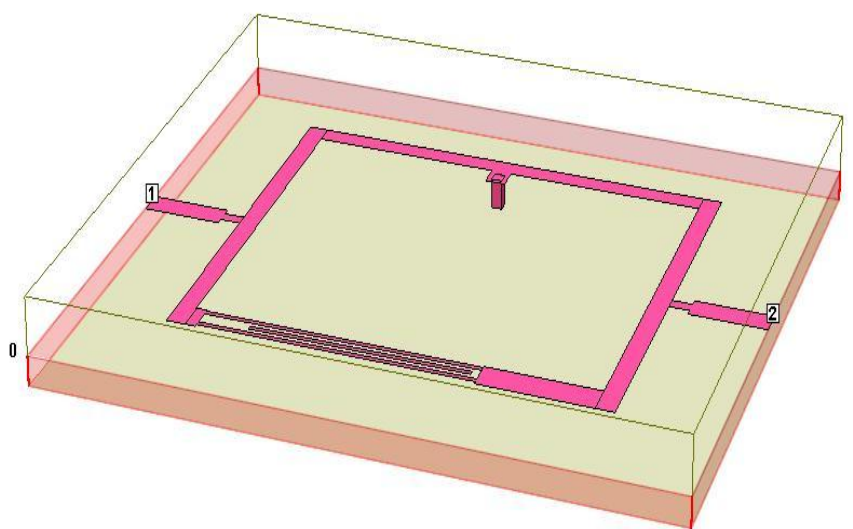

(C)

Table I R, L, C values as a function of laser power (Optical Switch)

\begin{tabular}{|l|ll|}
\hline \multirow{3}{*}{ ON $(200 \mathrm{~mW})$} & $\mathrm{L}_{\mathrm{B}}=41 \mathrm{nH}$ & $\mathrm{C}_{\mathrm{G}}=23 \mathrm{pF}$ \\
& $\mathrm{R}_{\mathrm{S}}=50 \Omega$ & $\mathrm{R}_{\mathrm{G}}=50 \Omega$ \\
& $\mathrm{C}_{\mathrm{P}}=23 \mathrm{pF}$ & $\mathrm{C}_{\mathrm{S}}=23 \mathrm{pF}$ \\
\hline \multirow{3}{*}{ OFF $(0 \mathrm{~mW})$} & $\mathrm{L}_{\mathrm{B}}=1 \mathrm{nH}$ & $\mathrm{C}_{\mathrm{G}}=1 \mathrm{pF}$ \\
& $\mathrm{R}_{\mathrm{S}}=800 \Omega$ & $\mathrm{R}_{\mathrm{G}}=800 \Omega$ \\
& $\mathrm{C}_{\mathrm{P}}=1 \mathrm{pF}$ & $\mathrm{C}_{\mathrm{S}}=1 \mathrm{pF}$ \\
\hline
\end{tabular}

Table II (Pin switch)

\begin{tabular}{|c|c|}
\hline $\mathrm{ON}$ & $\mathrm{OFF}$ \\
\hline $0.9 \Omega$ & $0.8 \mathrm{pF}$ \\
\hline
\end{tabular}

Figure 5 (a) Simulated s-parameter response of filter in the OFF/ON states using pin and optical switch (b) Measured s-parameter response of the fabricated filter in the ON/OFF states using pin and optical switch, and (C) 3-D view of the proposed filter.
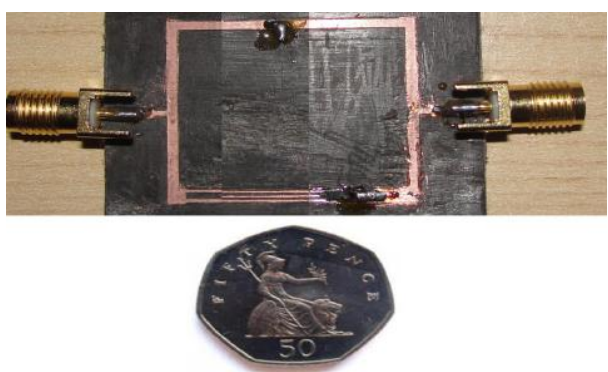

Figure 6 Photograph of fabricated filter 


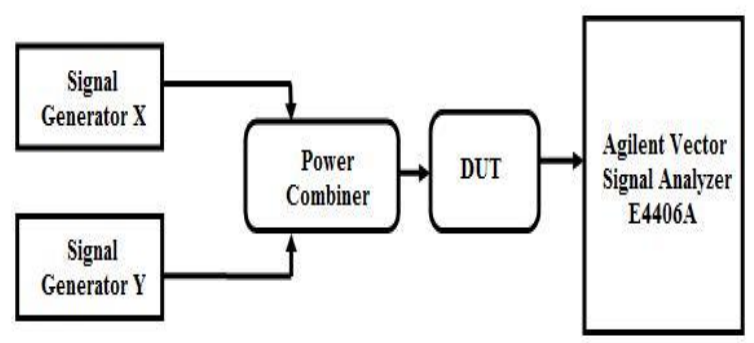

(a)

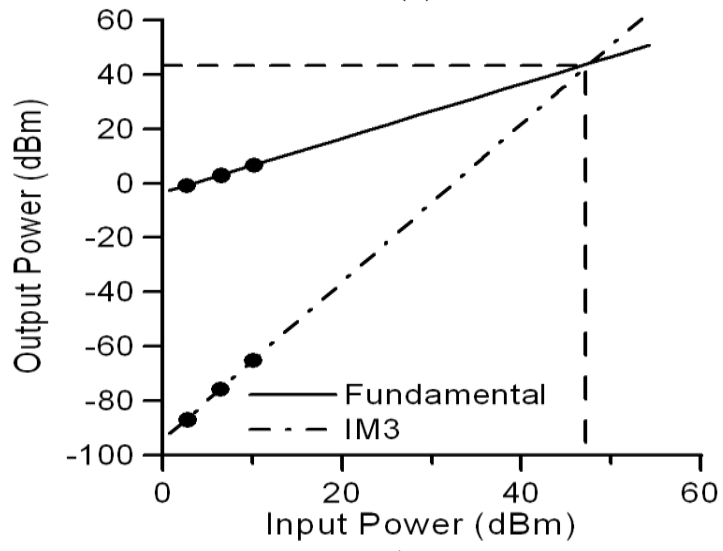

(b)

Figure 7 (a) Two-tone test setup, (b) Measured power of fundamental tones and thrid-order intermodulation product (IM3) plotted against input power for pin switch.

\section{CONCLUSION}

A highly linear reconfigurable microstrip bandpass filter is demonstrated. A single PIN diode (BAP65-02) or an optical switch is shown to reconfigure the notch within filter passband. In this experiment, the overall simulation results are in good agreement to the measurements for both the optical and pin reconfigurable filters. The linearity of the pin based filter is evaluated experimentally at various passband frequencies. The highly linear nature of the optical switch had already been verified. This high linearity reconfigurable filter has great potential in wideband based applications and the obtained results indicate that the proposed reconfigurable filter is suitable to be applied in the modern wireless systems.

\section{REFERENCES}

[1] Air Interface for Fixed Broadband Wireless Access Systems Amendment 2: Medium Access Control Modifications and Additional Physical Layer Specifications for 2-11 GHz, IEEE std. 802.16a, Part 16, 2003.

[2] A. Miller, J. S. Hong, "Wideband Bandpass Filter With Reconfigurable Bandwidth", IEEE Microw. And Wireless Comp. Lett., Vol. 20, No. 1, pp. 28-30, January 2010. 
[3] D. Draskovic and D. Budimir, "Optically controlled negative refractive index transmission lines”, European Conference on Antennas and Propagation, pp. 1672-1674, 2009.

[4] Y. H. Chun, H. Shamman, J. S. Hong, "Switchable embedded notch structure for UWB bandpass filter", IEEE Microwave and Wireless Component Letters, vol. 18, no. 9, pp. $590-592,2008$.

[5] P. W. Wong, I. C. Hunter, "Electronically Reconfigurable Microwave Bandpass Filter", IEEE Microw. Theory and Trans., vol. 57, no. 12, Dec. 2009.

[6] K. Rabbi, L. Athukorala, C. Panagamuwa, J. C. Vardaxoglou, and D. Budimir, "HighLinearity Reconfigurable Microstrip UWB Bandpass Filters", $6^{\text {th }}$ European Microwave Integrated Circuits Conference (EuMIC), pp. 172-175, Manchester, UK, October 2011.

[7] M. F. Karim, Y.X Guo, Z.N. Chan and L.C. Ong, "Miniaturized reconfigurable and switchable filter from UWB to $2.4 \mathrm{GHz}$ WLAN using PIN diodeds", IEEE MTT-S, pp. 509-512, 2009.

[8] G. L. Matthaei, L. Young and E.M.T. Jones, “Microwave Filters, Impedance-matching Networks and Coupling Structures”, McGraw-Hill, New York, 1964.

[9] B. E. Carey-Smith and P.A Warr, "Distortion mechanisms in varactor diode-tuned microwave filter", IEEE Trans. Microw. Theory Tech., vol. 54, no. 9, pp. 3492-3500, Sept. 2006.

[10] Emma K. Kowalczuk and Panagamuwa, Chintana, Rob D. Seager and Vardaxoglou, John C.(2010) “ Characterising the Linearity of an Optically Controlled Photoconductive Microwave Switch”. IEEE Loughborough Antennas and Propagation Conference (LAPC 2010), pp. 597-600, 8-9 November 2010.

[11] http://www.nxp.com/ 